\title{
PRODUCTION AND ANALYSIS OF ELECTROSPUN MATERIALS CONTAINING OXIDIC NANOPARTICLES
}

\author{
${ }^{1}$ Alexandra BENEDIKOVÁ, ${ }^{1} J a n$ GRÉGR, ${ }^{1}$ Martin STUCHLÍK, ${ }^{1}$ Pavel KEJZLAR, \\ ${ }^{2}$ Michaela KOZLOVSKÁ, ${ }^{1} E v a$ KUŽELOVÁ KOŠŤÁKOVÁ \\ ${ }^{1}$ Technical University of Liberec, Liberec, Czech Republic, EU, \\ alexandra.benedikova@tul.cz,jan.gregr@tul.cz,martin.stuchlik@tul.cz,pavel.kejzlar@tul.cz, \\ eva.kostakova@tul.cz \\ ${ }^{2}$ National Institute for Nuclear, Chemical and Biological Protection, Kamenná, Milín, Czech Republic, EU, \\ kozlovska@suichbo.cz
}

https://doi.org/10.37904/nanocon.2020.3702

\begin{abstract}
Metal oxides based on bismuth are considered to be potentially attractive candidates for developing new materials for radiation protection. In combination with electrospinning technology, it is possible to obtain interesting nanofibrous materials with high content of metal oxides based on bismuth nanoparticles in uniform distribution. This paper focuses on the fabrication and basic analysis of electrospun nanofibrous materials containing $\mathrm{Bi} 2 \mathrm{O} 3$ and $\mathrm{LuBiO} 3$ nanoparticles. The aim of the research was to optimized high nanoparticle concentration in nanofibrous material (more than $50 \mathrm{wt} \%$ ) via conventional needless electrospinning technology with optimal nanofibrous material morphology and uniform particle distribution.
\end{abstract}

Keywords: Nanofibres, PVA, oxidic nanoparticles, $\mathrm{LuBiO}_{3}, \mathrm{Bi}_{2} \mathrm{O}_{3}, \mathrm{X}$-Ray attenuation

\section{INTRODUCTION}

Recently, nanofibrous materials containing inorganic particles especially metal oxides have been investigated as a subject of various emerging applications or processes as for example gas sensors, ceramic biomaterials, magnetic membranes for medicine application, materials for visible-light responsible photocatalysts etc. [1-3]. However, there is also a possibility to use these composite nanofibrous materials with integrated metal oxide nanoparticles in the field of radiation protection [4]. Ionising radiation has accompanied human scientific and industrial activity for decades, nevertheless up to this date, a way to develop and produce a material that is non-toxic, light, breathable and protects against the negative effects of $X$-rays, is still being sought.

Currently, lead or patented composite materials [5] are used in the field of X-ray protection. Apart from the fact that lead is toxic to the human organism, there is a huge disadvantage of using these materials - lead sheets are extremely heavy because of their high density. Although polymer-based composites are more flexible and it is much easier to work with them and handle, they are still not sufficient. They are not breathable and flexible enough, which makes them very uncomfortable to wear. The solution could be based on nanomaterials. The enlarged particle surface and their dispersion in the polymer matrix can leads to a drastic reduction in material weight with equal efficiency and increased comfort. The most important is the uniform distribution of metal oxide nanoparticles over the material and relatively high content of particles in the final produced material, what is not easy task especially with regard to production on a larger scale, not only in laboratory one.

Following up on a previous research [6,7], the aim of this work is to fabricate and analyse PVB nanofibrous composites with incorporated heavy metal oxide nanoparticles (especially $\mathrm{Bi}_{2} \mathrm{O}_{3}$ and $\mathrm{LuBiO}_{3}$ ) for ionising radiation attenuation. This nanofibrous composite constitutes a breathable, flexible, lightweight, non-toxic layer of a 'smart uniform' that could be primarily used by for protection of special units of the state apparatus in 
dangerous environments. Nevertheless, it could possibly serve in many different fields of human activities as for example, as a protection of medical professionals when working with the risk of being exposed to X-rays.

In order to compare the effectiveness of radiation attenuation in prepared materials, it is necessary to mention some properties. Besides linear attenuation coefficient and mass attenuation coefficient, the most important property is the attenuation length. Attenuation length is characterised as the depth of penetration of radiation into the material at which the intensity of radiation is reduced to approximately $37 \%$ of the initial intensity [8]. Figure 1 shows that both bismuth oxide and lutetium oxide have significantly increased values of attenuation length for certain energies and form so-called absorption edges. The waveform is much smoother for the $\mathrm{LuBiO}_{3}$ oxide. If two or more heavy metal elements are combined in one oxide compound, the waveform is getting smoother. It means that there is not needed such a thick layer of material for the same attenuation effect.

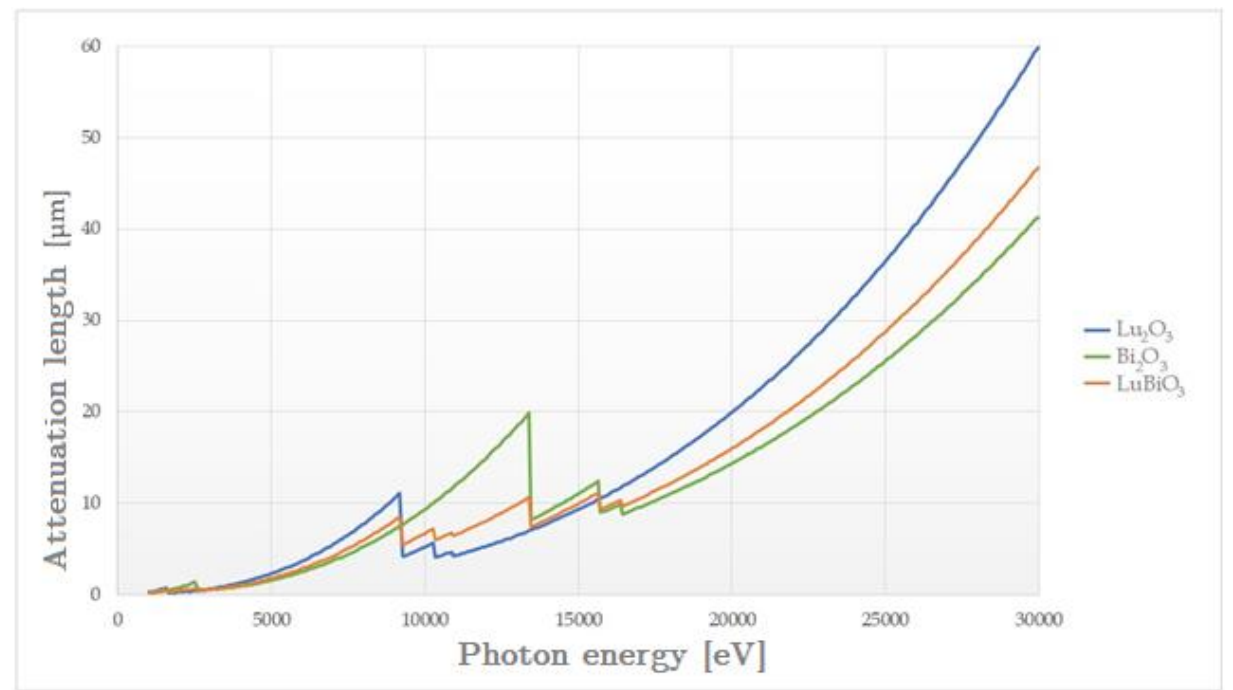

Figure 1 Attenuation length - photon energy graph: Parameters of oxides properties were specified on Web page [8] for $\mathrm{Bi}_{2} \mathrm{O}_{3}$ (density $8.9 \mathrm{~g} / \mathrm{cm}^{3}$ ), $\mathrm{Lu}_{2} \mathrm{O}_{3}$ (density $9.5 \mathrm{~g} / \mathrm{cm}^{3}$ ) and $\mathrm{LuBiO}_{3}\left(\right.$ density $9.4 \mathrm{~g} / \mathrm{cm}^{3}$ ). For scanning the energy the range from 30 to $30000 \mathrm{eV}$ in 100 steps at fixed angle $90^{\circ}$.

\section{MATERIALS \& METHODS}

In the study, two types of metal oxides nanoparticles based on bismuth were used, bismuth oxide $\mathrm{Bi}_{2} \mathrm{O}_{3}$ and bismuth lutetium oxide $\mathrm{LuBiO}_{3}$. Nanoparticles of bismuth oxide were purchased from Merck (nanopowder; 90-210 nm particle size, 99\% trace metals basis, Merck, CZ). Since the nanoparticles of $\mathrm{LuBiO}_{3}$ are not commonly available on the market, there was necessary to synthetize them in laboratory. Two methods of synthesis were used to prepare the $\mathrm{LuBiO}_{3}$ nanoparticles - self-combustion synthesis and coprecipitation method. The reagents used for these methods were pure bismuth oxide $\mathrm{Bi}_{2} \mathrm{O}_{3}$ (pure, PENTA, CZ) and lutetium oxide $\mathrm{Lu}_{2} \mathrm{O}_{3}(99,999 \%$, Cerac Inc., USA). For the self-combustion synthesis experiments, metal oxides were transformed into precursors in form of nitrates, $\mathrm{Bi}\left(\mathrm{NO}_{3}\right)_{3}$ and $\mathrm{Lu}\left(\mathrm{NO}_{3}\right)_{3}$ by mixing starting oxides with analytical grade nitric acid ( $65 \%$, LACH:NER CZ) and heating the mixture up. For self-combustion reactions, different fuels were chosen - glycine $\mathrm{CH}_{5} \mathrm{NO}_{2}$ (LACH:NER, CZ), citric acid $\mathrm{C}_{6} \mathrm{H}_{8} \mathrm{O}_{7}$ (LACH:NER, CZ) and tartaric acid $\left(\mathrm{C}_{4} \mathrm{H}_{6} \mathrm{O}_{6}, \mathrm{LACH}: \mathrm{NER}, \mathrm{CZ}\right)$. Nitrate precursors were mixed with fuel and the reaction was initiated. Afterwards, the mixture was processed in agate mortar and heated up to $800{ }^{\circ} \mathrm{C}$ in an electric furnace. For the coprecipitation method, nitrate mixture solution was added by drops from burette to a beaker placed on a magnetic agitator containing aqueous solution of ammonium hydroxide $\mathrm{NH}_{4} \mathrm{OH}$ (24\%, PENTA CZ). This process led to a white precipitate, that needed to be dried, and then it was placed into an electric furnace and heated up to $800{ }^{\circ} \mathrm{C}$. 
Polyvinyl butyral (PVB; Mowital B $60 \mathrm{H}$ ) manufactured by Kuraray was chosen as polymer material. The solvent for the spinning solutions was ethanol and the polymer concentration in the final solution was $10 \%$ by weight. The concentration of polymer dry matter to nanoparticles in the final solutions was chosen as follows: 1:0;1:3 and $1: 9$ by weight. An ultrasonic homogenizer was used to distribute the nanoparticles more evenly in the suspension to form a final stable solution necessary for needleless electrospinning technology. All the nanofibrous materials were processed by the electrospinning method on a needless electrospinning NS 1WS500U (Elmarco, CZ) device type. After the complex optimization process, the following process conditions were found. The spinning electrode was charged with a DC high voltage source positively $(30 \mathrm{kV})$ and the collector was charged negatively $(-10 \mathrm{kV})$. The distance between the spinning electrode and the collector was $180 \mathrm{~mm}$, the temperature during the spinning process was $22{ }^{\circ} \mathrm{C}$ and the relative humidity was $30 \%$. The used supporting material was spunbond (PFNonwovens, CZ) with $20 \mathrm{~g} / \mathrm{m}^{2}$ and withdrawal speed of supporting material was $10 \mathrm{~mm} / \mathrm{min}$.

The scanning electron microscopes were used for sample analysis to visualize the resulting nanoparticles and fibrous structures (FE-SEM Carl Zeiss ULTRA Plus and Tescan VEGA 3). Furthermore, the analysis of the chemical composition of the surface SEM-EDS analysis and TGA analysis (TGA 500, Ta Instruments) allowing the verification of the final amount of inorganic particles in spun nanofibers with temperature rise up to $650^{\circ} \mathrm{C}$ during sample weighing about $10 \mathrm{mg}$.

\section{RESULTS}

Both methods of $\mathrm{LuBiO}_{3}$ particles preparation led to a fine yellow powdered product that was analysed by XRD. On Figure 2, there is introduced the XRD analysis of self-combustion synthesis product prepared with tartaric acid as fuel. Figure 2 shows, that prepared nanoparticles crystallize in cubic lattice with parameter $\mathrm{a}=541 \mathrm{pm}$ and density $9.06 \mathrm{~g} / \mathrm{cm}^{3}$.
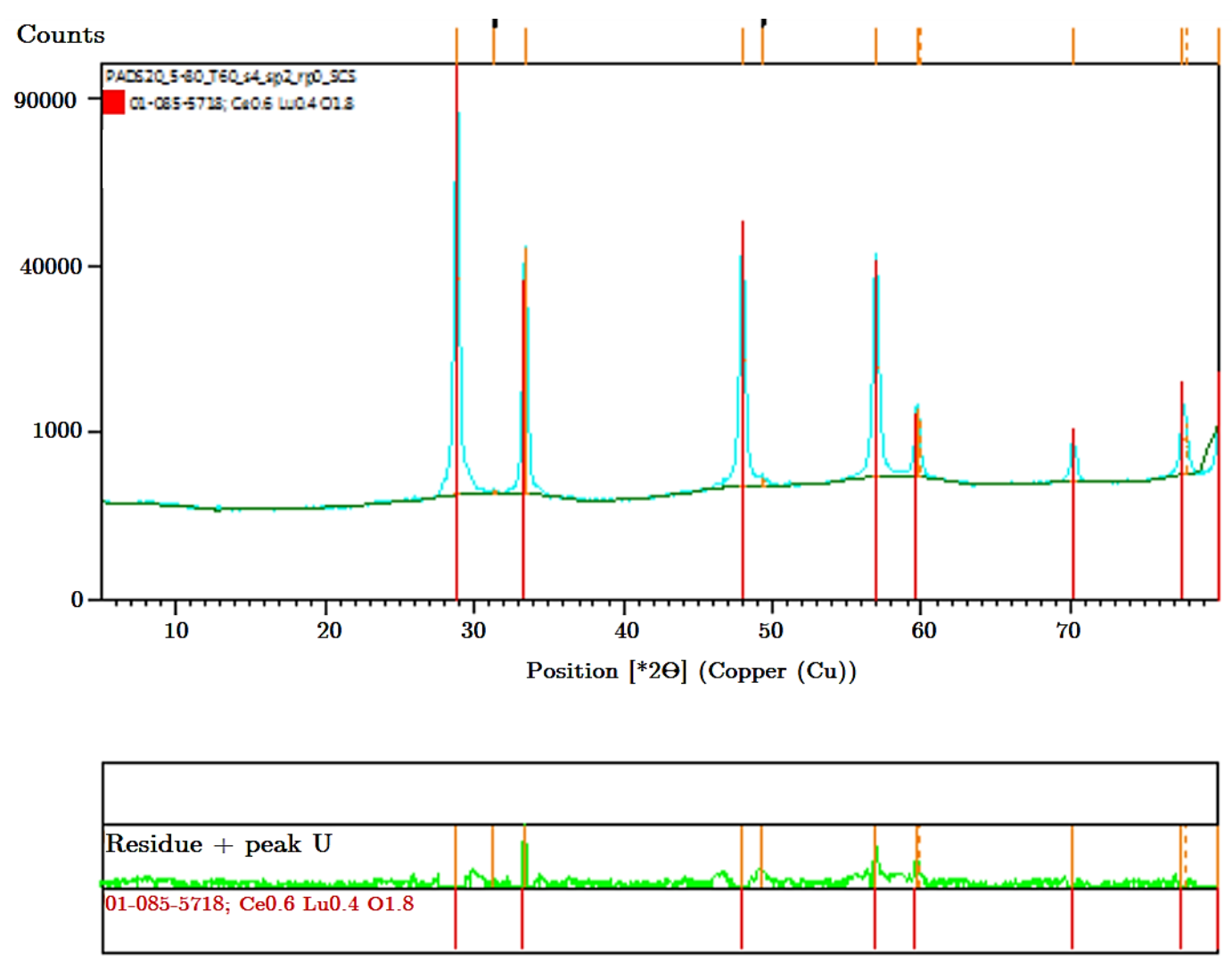

Figure 2 XRD analysis of self-combustion (tartaric acid) $\mathrm{LuBiO}_{3}$ nanoparticles 


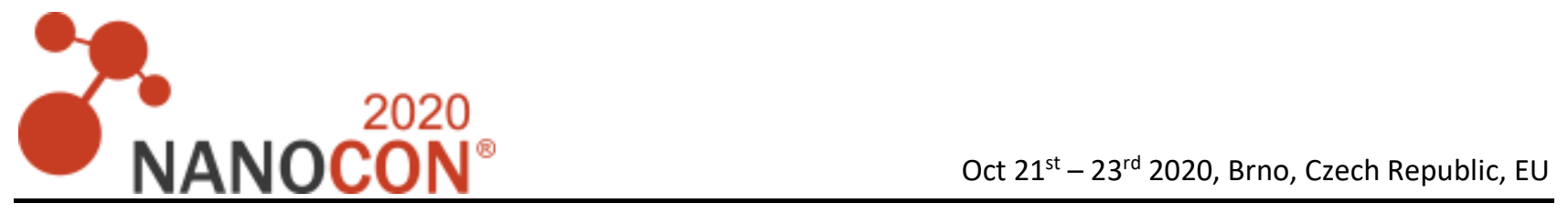

Obtained $\mathrm{LuBiO}_{3}$ as well as $\mathrm{Bi}_{2} \mathrm{O}_{3}$ nanoparticles are perfectly wettable in $\mathrm{PVB} /$ ethanol solution that was selected for electrospinning process. This property allows particles to be perfectly embedded in the resulting fibres. Most of the $\mathrm{LuBiO}_{3}$ particles are in range of $50-500 \mathrm{~nm}$. Both of the bismuth oxide particles are incorporated inside the electrospun material at all the concentrations very well (Figure 3).
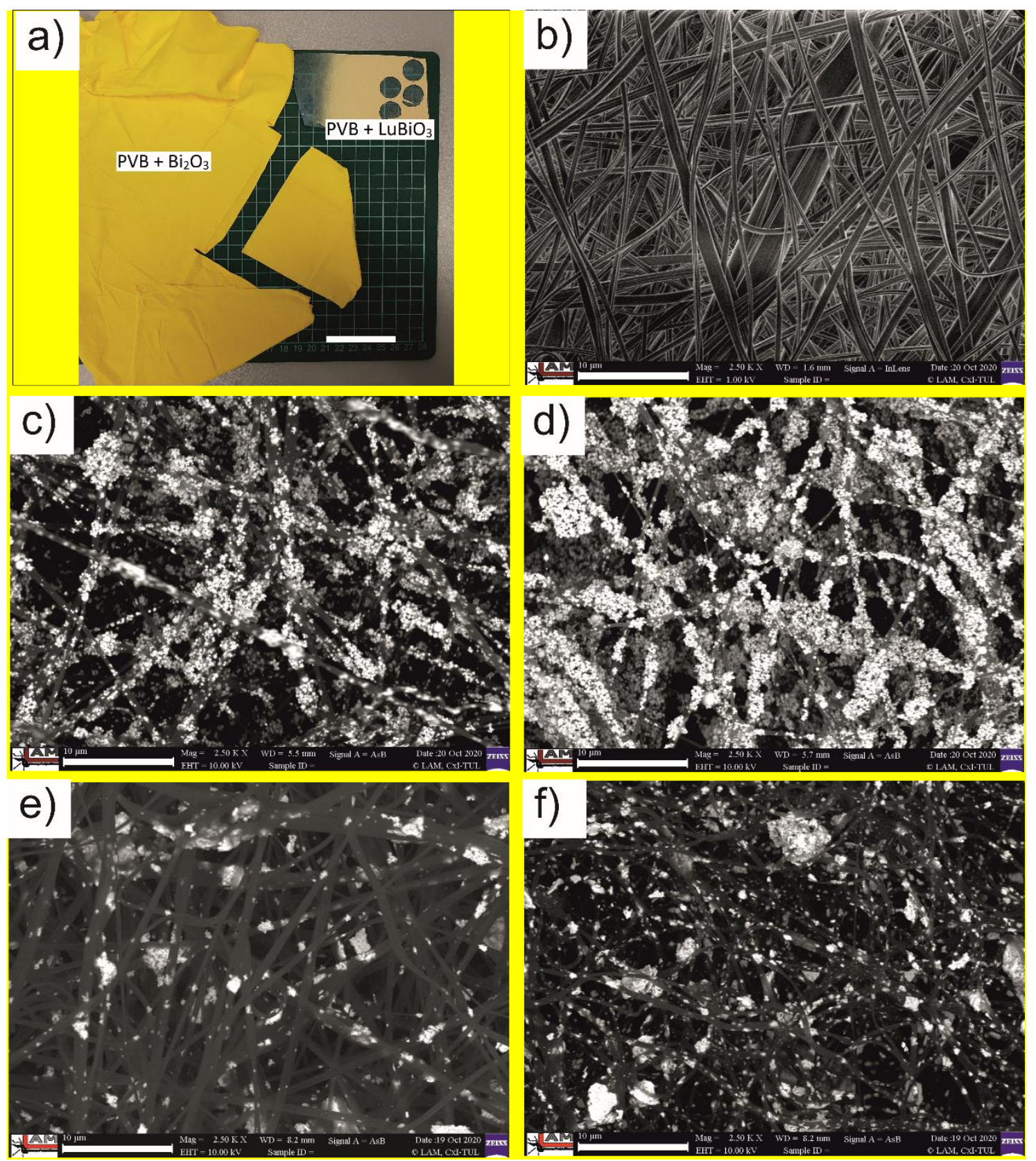

Figure 3 Electrospun materials: a) a photo of electrospun materials with $\mathrm{Bi}_{2} \mathrm{O}_{3}$ and $\mathrm{LuBiO}_{3}$ in polymer to particles ratio $1: 9$ by weight; b) SEM image of PVB electrospun materials without particles (blind sample); c) SEM image of $P V B$ with $\mathrm{Bi}_{2} \mathrm{O}_{3}$ nanoparticles in polymer to particles ration 1:3 by weight; d) SEM image of $\mathrm{PVB}$ with $\mathrm{Bi}_{2} \mathrm{O}_{3}$ nanoparticles in polymer to particles ration 1:9 by weight; e) SEM image of PVB electrospun material with $\mathrm{LuBiO}_{3}$ in polymer to particle ratio 1:3 and f) SEM image of PVB electrospun material with $\mathrm{LuBiO}_{3}$ in polymer to particle ratio $1: 9$ by weight. The scale bars show $5 \mathrm{~cm}$ (a) and 10 micrometres (b-f).

TGA analysis of all fabricated materials showed that real content of nanoparticles inside electrospun materials is exactly (for $\mathrm{Bi}_{2} \mathrm{O}_{3}$ ) or only a little smaller (for $\mathrm{LuBiO}_{3}$ ) than ratio of polymer dry matter to nanoparticle 
concentration in prepared solutions (Table 1). Table 1 also introduced individual surface densities of the electrospun materials with the same process parameters. The highest productivity, with the same electrospinning process parameters, was found for the material with integrated $\mathrm{Bi}_{2} \mathrm{O}_{3}$ nanoparticles. Their size was smaller and because of professional production, their distribution was not so wide.

Table 1 Comparison of chosen properties of fabricated basic and composite electrospun materials. The ratio PVB to particles represents the ratio in the original solutions for electrospinning by weight. TGA residue represents proof of real amount of particles in final electrospun nanofibrous materials. Volume ratio of particles inside fibre is calculated from the weight ratio and density. Final surface density of the electrospun materials was measured for each sample too.

\begin{tabular}{|l|c|c|c|c|}
\hline Sample & Ratio PVB:particles & TGA residue $(\mathbf{w t} \%)$ & Vol\% & $\begin{array}{c}\text { Surface density } \\
\left(\mathbf{g} / \mathbf{m}^{2}\right)\end{array}$ \\
\hline PVB & - & 0.79 & - & \\
\hline \multirow{2}{*}{ PVB $-\mathrm{Bi}_{2} \mathrm{O}_{3}$} & $1: 3$ & 75.8 & 25.6 & 102.4 \\
\cline { 2 - 5 } & $1: 9$ & 89.9 & 52.4 & 213.6 \\
\hline \multirow{2}{*}{$\mathrm{PVB}-\mathrm{LuBiO}_{3}$} & $1: 3$ & 58.9 & 24.9 & 25.57 \\
\cline { 2 - 5 } & $1: 9$ & 81.7 & 33.1 & 51.87 \\
\hline
\end{tabular}

The production study, which is mainly presented here, is added to illustrate the effect of medical diagnostic $X$-ray images. The electrospun materials were cut into pieces and put together in various numbers of layers to see how the attenuation effect would intensify. The effect of different number of electrospun material layers for the tested composite materials are visible in Figure 4.
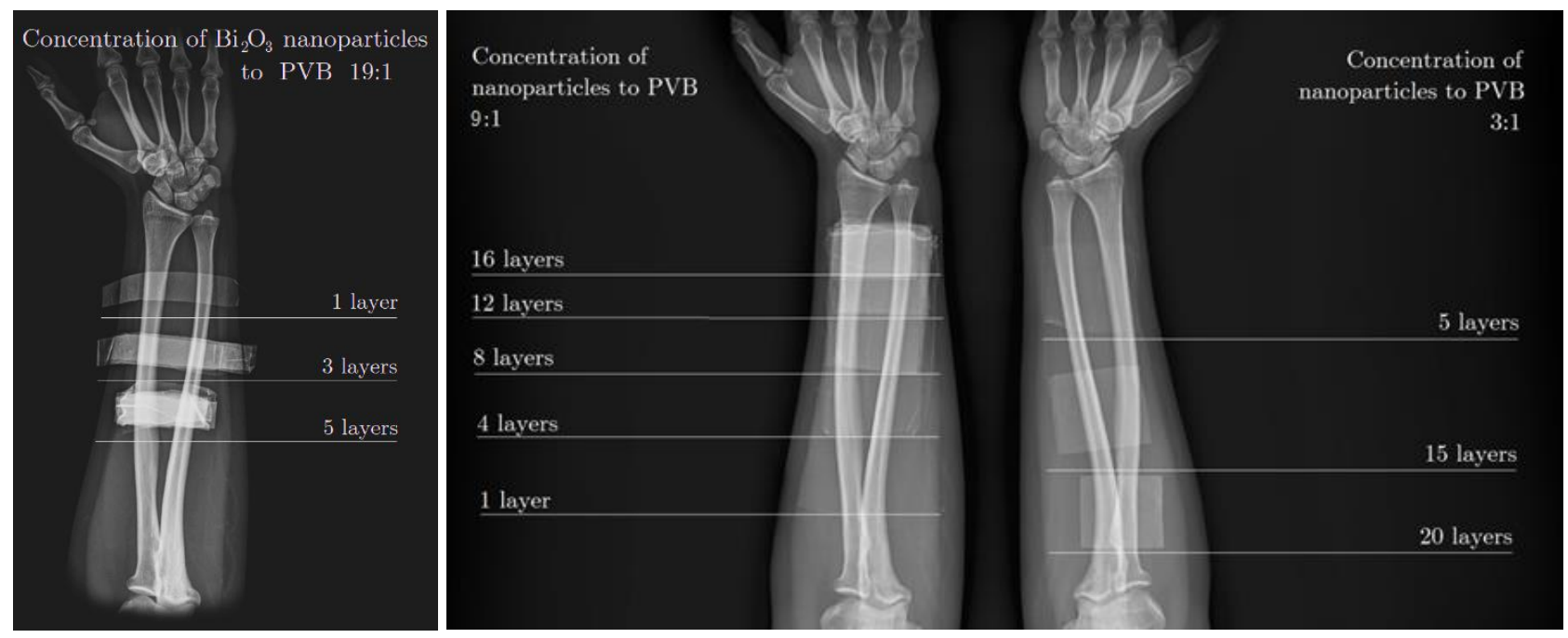

Figure 4 X-Ray image of radiation attenuation effect of electrospun PVB nanofibers with integrated nanoparticles $\mathrm{Bi}_{2} \mathrm{O}_{3}$ in polymer to particles ratio $1: 9$ by weight (left side) and electrospun PVB nanfoibers with integrated nanoparticles of $\mathrm{LuBiO}_{3}$ in polymer to particles ratios $1: 3$ and $1: 9$ by weight (right side)

\section{CONCLUSION}

Nanoparticles $\mathrm{LuBiO}_{3}$ were successfully prepared in nanometre size. Composite nanofibers containing two types of metal oxides based on bismuth $\left(\mathrm{Bi}_{2} \mathrm{O}_{3}\right.$ and $\left.\mathrm{LuBiO}_{3}\right)$ were successfully electrospun by needle-less electrospinning method. The optimization of the electrospinning technology was performed for pilot production and is therefore not limited to the laboratory production of small quantities of samples. The distribution of nanoparticles inside the nanofibers and all electrospun layer is uniform. The electrospun material contain 
almost all the particles, which were added into the solution what was confirmed by TGA analysis. The optimization of the electrospinning process and combination of the polymer, solvent and particles brings final materials, which are a good candidate as lead-free polymer/bismuth oxide based materials for use as potential $\mathrm{X}$-ray shielding materials, because of their good X-ray attenuation ability. The testing for specific applications in the field of radiation protection is going to continue this study.

\section{ACKNOWLEDGEMENTS}

\section{The result was obtained through the financial support of the grant "Intelligent textiles for protection against CBRN substances" of Ministry of Interior of the Czech republic; VI20172020059.}

\section{REFERENCES}

[1] ABIDEEN, Z.U., JAE-HUN, K., JAE-HYOUNG, L., JIN-YOUNG, K., ALI, M., HYOUN, W.K., SANG, S.K. Electrospun Metal Oxide Composite Nanofibers Gas Sensors: A Review. Journal of the Korean Ceramic Society. [online]. 2017, vol.54, no. 5, pp. 366-79. Available from: https://doi.org/10.4191/kcers.2017.54.5.12.

[2] IM, Y.M., TAE, H.O., JIN, W.Ch., YOUNG, H.S., JUN, S.H., JOSEPH, A.N., SUNG, S.H., SOON, H.J. Preparation of Poly(Vinyl Alcohol)/ZrO ${ }_{2}$ Composite Nanofibers via Co-Axial Electrospinning with Higher $\mathrm{ZrO}_{2}$ Particle Content. Fibers and Polymers. [online]. 2014, vol.15, no.10, pp. 2066-71. Available from: https://doi.org/10.1007/s12221014-2066-y.

[3] LIM, G.D., JAE-HYUN, Y., MYEONGJUN, J., YOUNG-IN, L. Visible Light Driven Photocatalytic Degradation Enhanced by $\alpha / \beta$ Phase Heterojunctions on Electrospun $\mathrm{Bi}_{2} \mathrm{O}_{3}$ Nanofibers. Journal of Alloys and Compounds. [online]. 2019, vol. 806, pp. 1060-67. Available from: https://doi.org/10.1016/j.jallcom.2019.07.319.

[4] HAZLAN, M.H., MUNIRAH, J., RAMZUN, M.R., NURUL, Z.N.A. X-Ray Attenuation Characterisation of Electrospun $\mathrm{Bi}_{2} \mathrm{O}_{3} / \mathrm{PVA}$ and $\mathrm{WO}_{3} / \mathrm{PVA}$ Nanofibre Mats as Potential X-Ray Shielding Materials. Applied Physics $A$. [online]. 2018, vol.124, no.7, p. 497. Available from: https://doi.org/10.1007/s00339-018-1915-8.

[5] DEMEO, R.J, KUCHEROVSKY, J., KURUPATHI, A. Radiation detectable and protective articles. Patent US20050211930A1. 29. 9. 2005. [viewed 2020-05-29]. Available from: https://patentimages.storage.googleapis.com/16/1a/3c/d8e88313f57847/WO2006069007A3.pdf.

[6] GRÉGR, J., MÉSZÁROS, L., KOZLOVSKÁ, M., HAVLÍČEK, K., KUŽELOVÁ KOŠŤÁKOVÁ, E. Electrospun Fibrous Materials with Integrated Inorganic Particles. In: Polymer Composites 2019. Tábor: Czech Technical University in Prague, 2019, pp. 23-28. ISBN 978-80-01-06582-2.

[7] BENEDIKOVÁ, $\mathrm{A} . \mathrm{LuBiO}_{3}$ nanoparticles for ionizing radiation attenuation. Liberec, 2020. Bachelor thesis. Technical university of Liberec.

[8] ANON. X-Ray Attenuation Length. [online]. [viewed: 2020-05-30]. Available from: https://henke.lbl.gov/optical constants/atten2.html. 